\title{
VOZES DOS RIBEIRINHOS MARAJOARAS Correspondências Entre História e Oralidade
}

\author{
Autora: Mônica de Jesus dos Anjos Nunes ${ }^{1}$ \\ Orientador: Msc. Luiz Guilherme Santos ${ }^{2}$
}

\begin{abstract}
Resumo: Alguns autores dizem sobre a vida de ribeirinho é cercada de contos "imaginários". Para entender tais narrativas, começamos uma pesquisa de cunho acadêmico pela UFPA PARFOR, onde o objetivo era ouvir, gravar e transcrever as "estórias" dos moradores mais velhos de um Rio chamado Jepohúba, na Ilha de Marajó. Bem como visitar os locais onde teriam acontecido os tais "fatos fantasmagóricos", que acabaram virando "contos" transmitidos através das gerações até os dias atuais. "A velha do poço", "escaléo encantado", "os botos da enseada", "o homem do caminho". São narrativas que surgem porque um caçador ao beber demais, dorme na mata e precisa justificar sua demora para a família, mas precisa que seja algo que não o envergonhe. Mas a "estória" é tão boa que um, conta para outros, de forma que até o próprio caçador passa a acreditar em sua veracidade. Daí surge às lendas que atravessam tempos e tempos como uma verdade extraordinária do ribeirinho Marajoara. Ou uma mulher que ao ficar muito tempo fora de casa, precisa chamar a atenção do marido para algo que não seja sua demora, então ela diz que ia atravessar o caminho mais próximo, mas avistou algo que a assustou muito e por isso demorou, então nasce "o homem do caminho". E os contos maravilhosos se tornam parte da história do homem marajoara que durante as "farinhadas", repassam de forma oral para as gerações seguintes.
\end{abstract}

Palavras - chave: Vozes, Memórias Imaginárias e Oralidade.

Summary: What the authors say about the life of riverine which is surrounded by tales "imaginary"?. To understand how and why such narratives emerged, we began a search for academic imprint UFPA - PARFOR, where the goal was to listen, record and transcribe the "stories" of the older residents of a Rio called Jepohúba in Marajó Island. As well as visiting the places where they would have happened such "ghostly facts" which ended up becoming "tales" passed down through the generations to the present day. "The old Pit", "escaléo delighted", "dolphins of the cove", "man's way." They are narratives that arise because a hunter to drinking too much, sleeping in the woods and need to justify his delay to the family, but that is something we need not be ashamed. But the "story" is so good that one account to another, so that even the hunter comes to believe in its truth. Hence arises the legends that cross time to time as a true extraordinary riverside Marajoara. Or a woman to stay too long away from home, needs her husband's attention to something other than being slow, then she says she would cross the path closest, but he saw something that scared her so much and took so born "man's way." And the wonderful tales become part of human history during which marajoara "farinhadas" pass down orally for generations to come.

Keywords - Keywords: Memories Oral Narratives and Imaginary

1- Professora da rede Pública. Formando em Letras pela UFPA - PARFOR

2- Professor da Universidade Federal do Pará - Campus Marajó/ BREVES 


\section{INTRODUÇÃO}

Este trabalho faz parte de uma pesquisa sobre as vivencias e imaginários dos ribeirinhos marajoaras. Para obter informações, cinco viagens foram realizadas para um rio chamado Jepohúba. Cada viagem teve duração de uma semana, onde se participou das farinhadas, pesca, baralhada e as idas e vindas as roças de mandioca para retirar o fruto e fabricar a farinha.

O Rio Jepohúba é uma pequena parte do Marajó, lugar tão rico em fauna, flora e narrativas quanto às demais localidades marajoaras. As narrativas trazem crenças tão maravilhosas que levam a imaginação do ser humano que as ouvem a um mundo de mistérios onde a realidade se confunde com o lendário, além de fazer com que seus pesquisadores esbarrem na história do Brasil, como a escravidão, já que os primeiros moradores ao povoarem o local em 1882, eram: Seu Esmeraldo um Negociador de escravos e Ricardinha, uma legitima escrava. Estes são personagens reais de uma história de lutas, conquistas e muitas narrativas orais.

O conto mais narrado no rio Jepohúba é: "O poço $\mathbf{d a}$ velha", onde um dos filhos de Esmeraldo supostamente teve o primeiro contato quando era apenas um rapaz. O lugar do poço é respeitado por todos, e causa medo em muitas pessoas que apenas ouvem. Os momentos onde são das narrativas, acontecem no momento em que fabricam a "farinha de mandioca”. Já que toda a família se reúne para ajudar.

\section{O RIBEIRINHO MARAJOARA}

Existem centenas de histórias e contos sobre o ribeirinho. Um caboclo que acorda cedo, que vai pescar, vai à roça ou se prepara para a caçada. A vida dessas pessoas não é fácil. Pois aqueles quando pescam, seja com "parí", "matapí", ou a "malhadeira", os perigos são muitos. Se vai para a roça fazer a farinha, o sol é implacável, as cobras sempre acham um calcanhar, formigas, um mato cortante por nome de tiririca, que não tem não tem nada de engraçado, o peso da mandioca no paneiro e doloroso e ainda tem os riscos de cortes com facões. Ainda tem as caçadas com os mesmos perigos da roça e mais o rico de serem atacado por um animal feroz, ou uma armadilha mal posicionada.

1- Professora da rede Pública. Formando em Letras pela UFPA - PARFOR

2- Professor da Universidade Federal do Pará - Campus Marajó/ BREVES 
Com todos esses riscos, o ribeirinho deveria ser um homem infeliz e amargurado. Mas não é. Ele recebe os visitantes sempre com um sorriso no rosto e uma boa xicara de café. E para deixar mais a vontade o forasteiro, sempre tem um bom conto para narrar, o que nos fazem viajar para um mundo onde se misturam realidade e imaginação.

O pensador Frances Michel Maffesoli em uma entrevista a Revista Famecos sobre o imaginário e a realidade diz:

"Em geral, opõe-se o imaginário ao real, ao verdadeiro. O imaginário seria uma ficção, algo sem consistência ou realidade, algo diferente da realidade econômica, política ou social, que seria, digamos, palpável, tangível”.

Apesar de se perceber as narrativas como algo ficcional e imaginário, para quem vive essa realidade é verdadeiro. As pessoas ribeirinhas se apegam as crenças de uma forma que confundem o real e o irreal.

Para realizar essa pesquisa foi necessário um longo tempo de convivência com o povo ribeirinho do rio Jepohúba, nesse período com a observação se obteve muitas informações. Por exemplo: "A benzedora" é uma pessoa que é presente na vida de todos, católicos ou não. Se a cobra pica, se há "mal olhado", se o marido bebe, se a mulher trai, se a caça vai ruim, se a pesca esta mal, em fim, sempre chamam a "benzedora". No rio, quem pertence a esse papel é uma senhora chamada "Emília". Senhora amável que atende a todos com carinho e dedicação. A esta figura se remete muitas das aparições sobre a velha do poço.

O imaginário do ribeirinho é real em seu dia-a-dia. Por mais que autores afirmem na ficção, que não há verdade, que é apenas usado como uma forma de explicar o irreal, para as pessoas que vivem o dia-a-dia nas comunidades ribeirinhas é real.

\section{COMO COMEÇOU A POPULAÇÃO JEPOHÚBANA:}

\section{Narrado por D. Olgarina (93 anos), Barreto. Neta de Esmeraldo e Ricardinha.}

Nessa parte da Narrativa há fatos que esbarram na história geral do Brasil, como a escravidão e de supostos personagens que fizeram parte da família fundadora da cidade de Breves - Pará, no Marajó. Esses fatos eram contados a Olgarina (uma das narradoras, falecida no meio da pesquisa), e seus irmão, quando ainda eram crianças pelo pai, o Sr. Aristides Anjos.

Para Ecléa Bosi, em Memória e sociedade:

1- Professora da rede Pública. Formando em Letras pela UFPA - PARFOR

2- Professor da Universidade Federal do Pará - Campus Marajó/ BREVES 
“a criança recebe do passado não só os dados da história escrita; mergulha suas raízes na história vivida, ou melhor, sobrevivida, das pessoas de idade que tomaram parte na sua socialização. Sem estas haveria apenas uma competência abstrata para lidar com os dados do passado, mas não a memória"

(BOSI, 1994, p. 73).

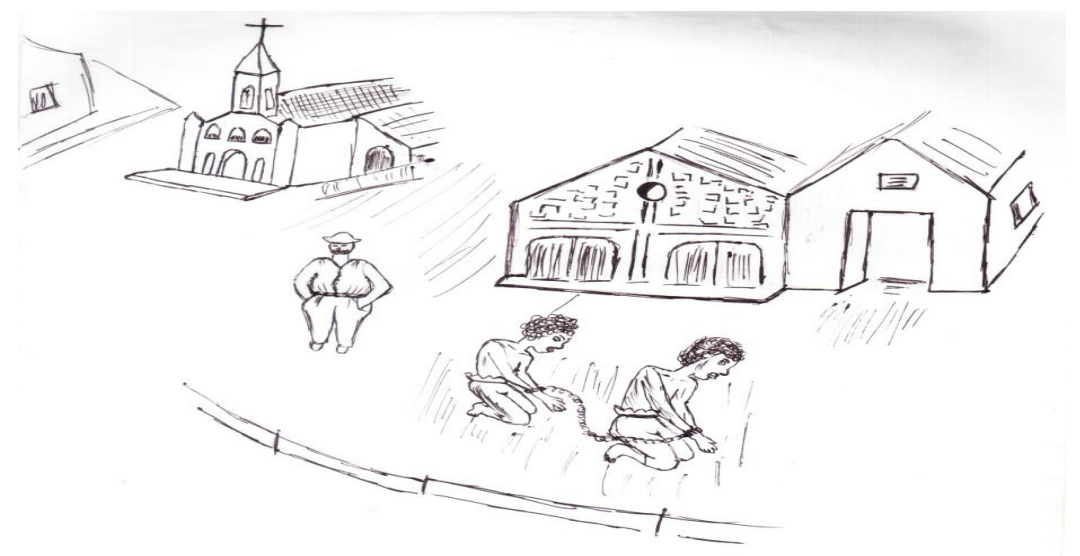

Ilustração sobre o Município de Breves - Marajó, no ano de 1826.

"Lugar dos Breves"

(Desenho de Sâmela Anjos)

1826, "Lugar de Santana dos Breves", a sudoeste do Marajó, habitado por donos de roças de café, pimenta - do - reino e cana de açúcar. Parte do Município de Melgaço. Uma jovem senhora se dizia dona de quase todas as terras de Breves. Boatos afirmavam que a mesma era descendente dos Breves. Saturnina Tereza era seu nome, mas muitos forasteiros que passavam iam se instalando e aos poucos a mulher foi perdendo suas posses.

O marido da suposta Sr. ${ }^{a}$ Breves não entendia de terras e sim de comércio com vendas de mercadorias e bebidas. Com isso faltava um homem para trabalhar nas propriedades e Saturnina por não saber ler acabou enganada por alguns Portugueses que barganharam suas terras por mixaria.

O lugar dos Breves era rústico com uma população pequena e sem tecnologia alguma. $\mathrm{O}$ único meio de saber das notícias era um único rádio que um navegante possuía. Uma bugiganga enorme, alimentada por uma bateria também de tamanho exagerado. Dessa forma as pessoas só se comunicavam com outras localidades, através de —missivas (cartas), enviadas por mensageiros que iam e vinham nas navegações que passavam. Estas barcas transportavam mercadorias e escravos.

Breves as margens do rio Parauaú, tinha apenas três ruas. A que fazia frente para o rio era povoada por alguns poucos forasteiros que fizeram casas e os taberneiros, comerciantes que vendiam mantimentos e bebidas. Dentre estes, havia Chico Reis, um homem rico e

1- Professora da rede Pública. Formando em Letras pela UFPA - PARFOR

2- Professor da Universidade Federal do Pará - Campus Marajó/ BREVES 
autoritário, dono de uma taberna localizada onde hoje funciona o supermercado Caramês. Era marido de Saturnina e pai de três filhos. Chico como outros comerciantes, adquiria as mercadorias através de um navegante escravocrata chamado Esmeraldo José Antônio dos anjos, que era responsável pela compra e venda de muitos utensílios, entre estes, negros para trabalharem nas roças dos senhores desta região.

Esmeraldo era um homem de semblante rude, grosseiro nos gestos e acostumado a castigar negros fujões, mas de uma inteligência astuta e eficaz para os negócios, muito trabalhador, sabia fazer de tudo um pouco e conhecia todos os segredos da terra para se ter boas plantações. Como diziam os antigos:

- Tinha Mão boa pra terra...

$\mathrm{Na}$ história geral do Brasil se percebe a escravidão de forma intensa. Os negros viviam em senzalas sem nenhum recurso humano. Os homens, algumas mulheres e crianças trabalhavam muitas horas por dia sem uma alimentação adequada, era uma verdadeira crueldade. E neste enredo, Haviam também os mercadores de escravos. Eram donos de embarcações que viajavam negociando mercadorias e "peças" (negros escravos), para seus patrões, que faziam encomendas.

Esmeraldo José era navegante. Quando ainda era criança perdeu pai e mãe, vítimas de malária, eles eram europeus em busca de riquezas no Brasil. O rapaz teve que aprender muito cedo a sobreviver, como o pai lhe deixara um barco, se tornou mercador de escravos. Até os dezesseis anos vivia sob a responsabilidade de outro escravocrata conhecido de sua família, com o qual aprendeu os ofícios da navegação, a fazer contas e a trabalhar na terra. O tutor de Esmeraldo não fora um carrasco, mas não aliviou nenhum pouco sua vida, fazendo com que se tornasse muito rude e desprovido de qualquer ação de carinho com outras pessoas.

Após a morte do homem que o criara, Esmeraldo continuou com o trabalho em viagens de compra e venda de mercadorias, foi em uma dessas viagens que trouxe um pagamento de uma dívida a Chico Reis. Uma escrava chamada por todos de "Ricardinha".

A pobre moça nasceu no auge da escravidão, na senzala de uma fazenda no sul do país, um ano antes da criação da lei do ventre livre surgir. Com apenas quinze anos, já trabalhava feito homem nas colheitas de café, mas a fazenda onde nascera estava em decadência e seu dono devia para muita gente, inclusive Chico Reis.

O Brasil estava em fase de erradicação do tráfico de escravos, muitas pessoas se uniam para acabar com os maus tratos sofridos pelos negros, e diante do avanço dos movimentos

1- Professora da rede Pública. Formando em Letras pela UFPA - PARFOR

2- Professor da Universidade Federal do Pará - Campus Marajó/ BREVES 
contra a escravidão e a pressão para que o tráfico acabasse, muitos fazendeiros que dependiam do trabalho dos negros, faliam ou negociavam suas peças em pagamento de dívidas. $\mathrm{E}$ foi assim que a negra Ricardinha veio parar em Breves, em pagamento de um fazendeiro falido a Chico Reis. E fora Esmeraldo o responsável pelo transporte da escrava até o seu novo dono.

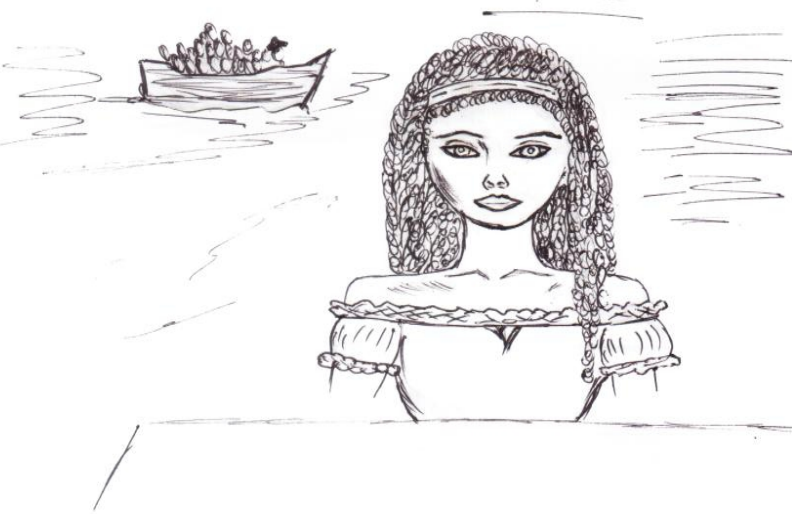
Ilustração da escrava Ricardinha

(Desenho de Sâmela Anjos)

Ricardinha foi roubada por Esmeraldo e levada para um rio chamado "Jepohúba", onde durante anos trabalharam para transformar o local em um ambiente de moradia, onde tiveram vários filhos, netos, bisnetos. E famílias que vivem até hoje.

Desde a antiguidade, muitas narrativas foram surgindo com as vivencias, nas caçadas, roças e pescarias.

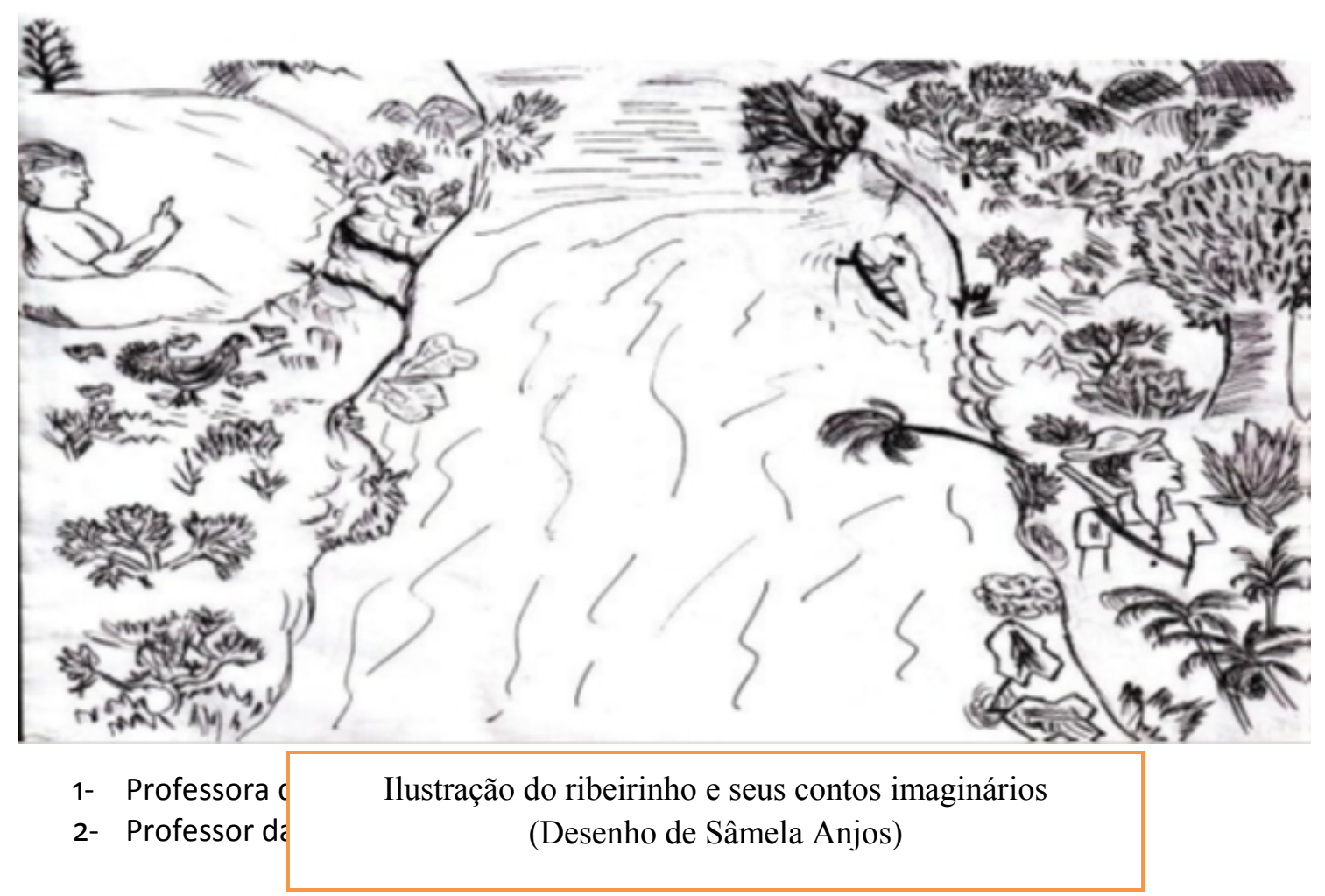




\title{
4. Correspondências Entre História e Oralidade
}

O ribeirinho tem um jeito só seu de fazer uma narrativa, o olhar demonstra para o ouvinte o medo que ele sentiu quando o fato narrado "aconteceu". Dessa forma quem pretende gravar ou apenas ouvir uma estória, precisa ter ética acima de tudo respeitar quem conta a narrativa.

Pessoalmente, se afirma que o interesse nas narrativas não é apenas de cunho acadêmico. Há por traz de tudo, um grande amor pelo ser, ribeirinho, pela forma de vida, pelas narrativas, em fim por tudo. Por este motivo o confronto com as pessoas das localidades ribeirinhas foi extremamente fácil e prazeroso. Pois os momentos de rememoração, fazem com que o ouvinte embarque no imaginário real do ribeirinho.

Segundo Fiorin (2001):

\begin{abstract}
"uma das formas de rememoração mais presentes na literatura é a retomada dos mitos, os quais seriam predecessores da história. Isto somente se dá graças à memória mítica, que não deixa de ser, também, uma espécie de memória coletiva, haja visto que, antes do surgimento da ciência, era por meio do mito que o homem buscava explicar os acontecimentos".
\end{abstract}

As pessoas da cidade, não conseguem mais vivenciar os momentos proporcionados pela imaginação. A vida passa tão rápida e há tanta coisa a fazer, que impedem estes momentos, que ainda podem ser encontrados nos ribeirinhos.

A senhora Ólgarina Barreto (93 anos, falecida durante a finalização das pesquisas em 2012), Laurici Anjos (56 anos) e Alexandrina Anjos (90 anos), são as principais narradoras das histórias e estórias da localidade. Foi com elas que se obteve a maioria das narrativas, mas pelo fato da pesquisa ter se alongado por dois anos, se conviveu com outros moradores, que por sua vez confirmaram algumas narrativas e contaram outras. Em todas sempre havia um conselho, ou a demonstração de valores como respeito, confiança, coragem, companheirismo.

As narrativas também servem para justificação de um ato ou um "erro". Por exemplo: Um dos moradores que não autorizou a exposição de seu nome, relatou um fato que aconteceu com ele. Todo ano acontece uma festa na comunidade intitulada de "Festa de São Miguel".

1- Professora da rede Pública. Formando em Letras pela UFPA - PARFOR

2- Professor da Universidade Federal do Pará - Campus Marajó/ BREVES 
Este cidadão deveria vir apenas para a reza, mas começou a tomar umas "biritas" (como chamam para a cachaça) e ao voltar já embriagado teria que atravessar o tal "caminho encantado". O homem segundo a esposa, chegou pálido, nadando, porque ao atravessar o caminho, lhe apareceu um homem de branco que teria assombrado o seu caminho. Fez-se segundo o homem, uma grande barulheira na mata ao redor do caminho e quando este levantou o olhar, viu o homem de branco. O pobre homem "bêbado" e assustado correu tanto que ao chegar do outro lado do caminho não teria tido tempo para pegar a canoa, já que a assombração vinha em seu encalço. Então se jogou na água e foi nadando até sua residência.

Em todas as narrativas há a presença de uma situação problema por traz. É como se o fato de assombração desviasse as possíveis discussões sobre a bebedeira do marido que não deveria ter ficado na festa, ou de uma caçador que não conseguiu a comida do dia seguinte ou de jovens enamorados que querem desviar a atenção dos pais. Mas são tão bem contadas que a partir da segunda vez que é narrada, acaba se tornando verdade. De forma que ninguém tem coragem ou argumento para desmentir um fato narrado, ao contrário, são fatos reais para os ribeirinhos que vivem nos locais, se tornando parte de suas próprias histórias de vida.

\subsection{AVELHA DO POÇO (Narrado por Laurici Anjos)}

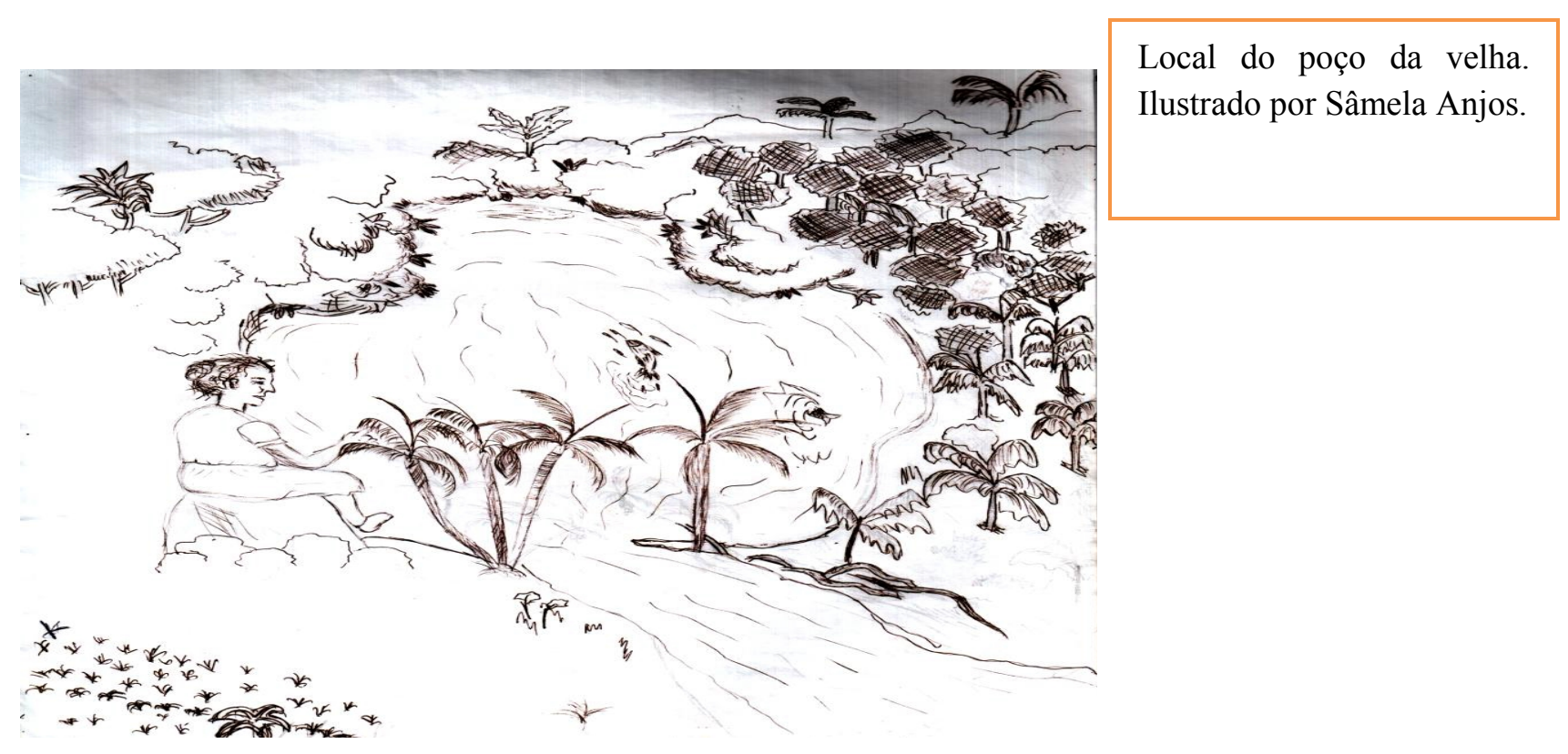

A velha do poço é o conto mais antigo do rio, existe desde 1826, ano que o rio começou a ser povoado por Esmeraldo (um mercador de escravos, de tabaco e café) e

1- Professora da rede Pública. Formando em Letras pela UFPA - PARFOR

2- Professor da Universidade Federal do Pará - Campus Marajó/ BREVES 
Ricardinha, uma escrava que teria pertencido a Saturnina Pereira, suposta ultima descendente dos Breves, fundadores do Município.

Este conto surgiu, quando o filho de Esmeraldo, Aristide em uma noite de lua cheia, avistou a aparição de uma mulher idosa no rio Jepuhuba. A velha teria passado em frente a residência da família de Aristide, este por sua vez, não reconhecendo a mulher a seguiu em uma canoa e sem que ela demonstrasse nenhum incomodo por ser seguida, meia hora depois, parou a canoa e entrou na mata e não voltou. O rapaz vendo que a figura sinistra não voltava, entrou na mata e encontrou um poço de águas azuis. A partir desse dia, muitas aparições aconteceram, dezenas de pessoas viram, navios brilhantes, galinha cantando, vozes que são contadas por caçadores e pescadores que se arriscam passar por lá em noites de lua cheia. E pelo menos uma vez no mês, um casal de boto passa pela casa, no rio e vai até ao poço. $O$ fato acontece sempre na quinta feira as seis da tarde e eles voltam na sexta feira às seis da manhã.

\subsection{A FARINHADA (Observado por Mônica Anjos)}

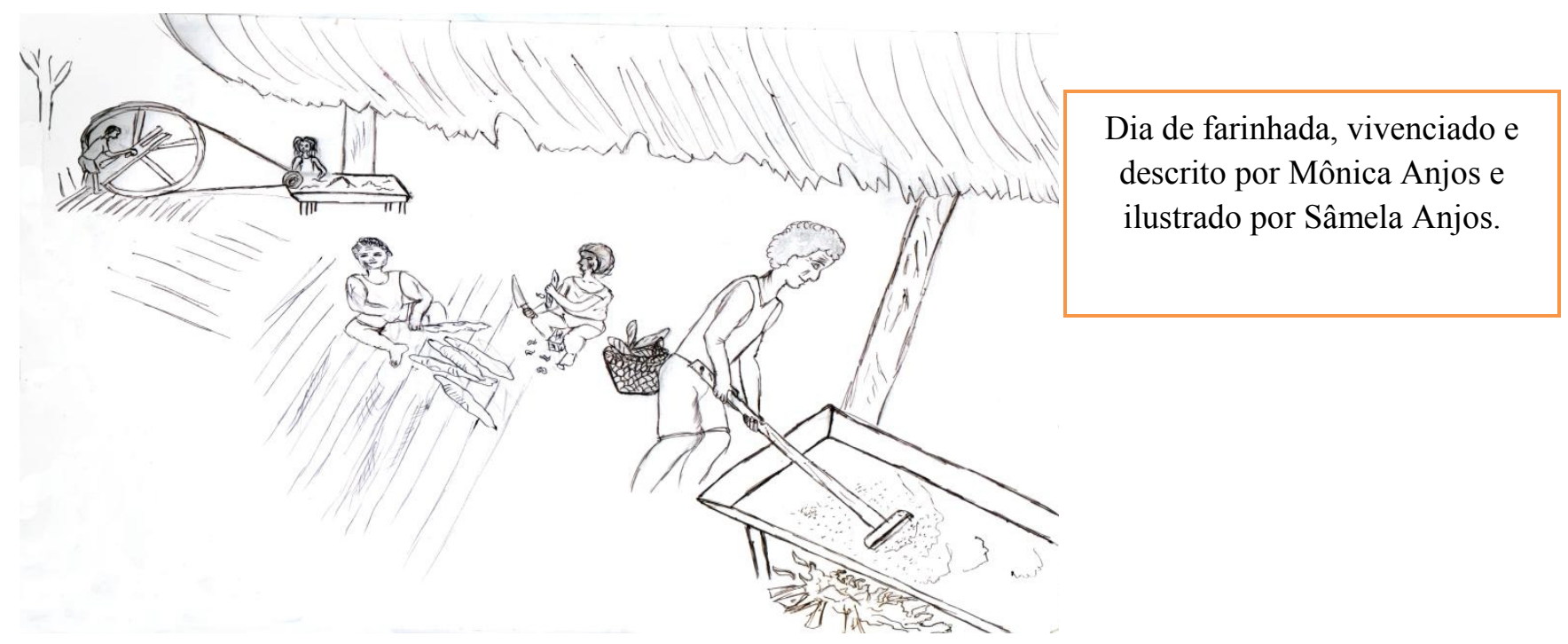

Muitas pessoas que gostam de farinha de mandioca branquinha, torradinha, não imaginam os tantos processos que levam. Muito suor é gastado até chegar ao pirão no prato. $\mathrm{E}$ durante o processo de fabricação os mais velhos aproveitam para relembrar velhos contos e repassar valores, pois se percebe que sempre que um jovem tenta desrespeitar as crenças ou desobedecer a ordens, uma pessoa mais velha conta um caso que teria acontecido com um antepassado e reforça a importância de não se quebrar velhos hábitos de convivência com a natureza e com outras pessoas da comunidade.

1- Professora da rede Pública. Formando em Letras pela UFPA - PARFOR

2- Professor da Universidade Federal do Pará - Campus Marajó/ BREVES 
Foi durante as idas as roças e durante as farinhadas que se ouviu sobre os contos não registrados que os mais velhos repassam aos jovens, como "o escaléu encantado", onde em noites escuras de uma determinada casa, as pessoas ouviam rezas, e cantigas e quando se aproximava da meia noite o "escaléu" (barquinhos), cheio de pessoas passava, na frente deste ia um galo cantando.

Outra estória é do "caminho encantado", onde segundo muitos moradores afirmam que antigos "cabanos" (membros da revolução da cabanagem), ao fugir da derrota, se esconderam no rio Jepohúba. Neste caminho teriam enterrado ouro e matado as pessoas que enterraram, estas seriam as assombrações que aparecem até os dias de hoje. Em entrevista a três famílias, pelo menos duas pessoas de cada família, afirma ter visto assombrações no "caminho".

\section{CONCLUSÃO}

O ribeirinho marajoara é um ser encantador, suas narrativas nos levam para o mundo imaginário do que é encantado, assombroso e magnifico. No entanto de tudo querem apenas chamar a atenção daqueles que deixaram de pensar para viver o corre-corre das cidades. As pessoas já não sentam com seus filhos para contar uma história ou um conto. Os mais jovens já não se preocupam nem valorizam os mais velhos, porque não tem tempo. Sempre tem baladas, passeios, amigos e namoradas para curtir. A sociedade em geral, não tem mais tempo nem paciência para ouvir, pois tem muito a falar o tempo todo. Com isso a imaginação fica restrita apenas ao trabalho, em ganhar dinheiro em sobreviver... Em viver.

Quantas histórias morrem todos os dias porque uma criança prefere a internet do que ouvi-la de um velhinho? Mas no jornal da noite existem noticias de idosos sendo maltratadas, crianças sendo violentadas, e mais e mais violências. Não se afirma aqui que entre os ribeirinhos há apenas honestidade e vida de respeito. Mas se atenta para valores a muito tempo esquecido pelas famílias.

O tempo que se passou com as pessoas do rio Jepuhúba proporcionou auto avaliação da vida e de valores. O ribeirinho com sua simplicidade, tem mais a ensinar do que achamos que devem aprender. Podem não usar a Língua portuguesa gramaticalmente correta, mas ainda vivem com muita sabedoria.

\section{REFERENCIAS}

1- Professora da rede Pública. Formando em Letras pela UFPA - PARFOR

2- Professor da Universidade Federal do Pará - Campus Marajó/ BREVES 
FAMECOS, Revista. O imaginário é uma realidade. Porto Alegre $\mathrm{n}^{\circ} 15$ de agosto 2001. Quadrimestral

BOSI, Ecléa. Memória e sociedade: lembranças de velhos. São Paulo: Companhia das letras, 1994.

FIORIN, José Luiz. In principio erat verbum. In: As astúcias da enunciação. São Paulo: Ática, 2001. 